\title{
The HOTAIR IncRNA: A remarkable oncogenic promoter in human cancer metastasis (Review)
}

\author{
LILI CHEN ${ }^{*}$, XINLE QIAN* ${ }^{*}$ ZHONGQI WANG and XIQIU ZHOU \\ Department of Medical Oncology, Longhua Hospital, \\ Shanghai University of Traditional Chinese Medicine, Shanghai 200032, P.R. China
}

Received September 12, 2020; Accepted December 23, 2020

DOI: $10.3892 / \mathrm{ol} .2021 .12563$

\begin{abstract}
Long non-coding RNA (lncRNA) is a new type of non-coding RNA that has an important regulatory influence on several human diseases, including cancer metastasis. HOX antisense intergenic RNA (HOTAIR), a newly discovered IncRNA, has an important effect on tumour proliferation, migration and metastasis. HOTAIR regulates cell proliferation, changes gene expression, and promotes tumour cell invasion and migration. However, its molecular mechanism of action remains unknown. The present review summarizes the molecular mechanism and role of HOTAIR in tumour invasion and metastasis, discusses the association between HOTAIR and tumour metastasis through different pathways, such as the transforming growth factor $\beta, \mathrm{Wnt} / \beta$-catenin, $\mathrm{PI} 3 \mathrm{~K} / \mathrm{AKT} / \mathrm{MAPK}$ and vascular endothelial growth factor pathways, emphasizes the function of HOTAIR in human malignant tumour metastasis and provides a foundation for its application in the diagnosis, prognosis and medical treatment of various tumours.
\end{abstract}

\section{Contents}

1. Introduction

2. TGF- $\beta$ pathway

3. Wnt/ $\beta$-catenin pathway

4. PI3K/AKT/MAPK pathway

5. Vascular endothelial growth factor (VEGF) pathway

Correspondence to: Professor Zhongqi Wang or Professor Xiqiu Zhou, Department of Medical Oncology, Longhua Hospital, Shanghai University of Traditional Chinese Medicine, 725 Wanpingnan Road, Shanghai 200032, P.R. China

E-mail: aledx@sina.com

E-mail: zhouxiqiu1970@aliyun.com

*Contributed equally

Key words: HOX antisense intergenic RNA, tumour metastasis, TGF- $\beta$ signalling pathway, Wnt/ $\beta$-catenin signalling pathway, PI3K/AKT/MAPK signal pathway, VEGF signalling pathway
6. Others

7. Prospects and challenges

\section{Introduction}

Cancer is a high mortality malignant disease with biological characteristics, such as abnormal cell differentiation and proliferation, uncontrolled growth, invasiveness and metastasis. Several patients with cancer have different degrees of metastasis following diagnosis or treatment $(1,2)$. Thus, cancer is an important cause of mortality and high-cost medical expenses (3). Tumour occurrence is associated with the expression levels of tumour suppressor genes and oncogenes (4-6). Accordingly, it is essential to identify biomarkers for the early diagnosis and prognosis of cancer, and to develop effective therapies to prolong the overall survival time of patients with cancer. The human genome is pervasively transcribed, while $<2 \%$ transcripts encode proteins. According to their size, non-coding RNAs (ncRNAs) are subdivided into two major categories: Short ncRNAs [sncRNAs, $<200$ nucleotides (nt)] and long ncRNAs (lncRNAs, >200 nt). MicroRNAs (miRNAs/miRs) and endogenous short interfering RNAs are sncRNAs (7). MiRNAs are short single-stranded RNA sequences (usually 19-23 nt) from a precursor of $\sim 70 \mathrm{nt}$, which can control gene expression during several physiological and developmental processes, thus, they play vital roles in post-transcriptional regulation by directly binding the miRNA response element in target mRNAs (8-10).

lncRNAs include multiple well-studied ncRNAs, such as the most representative, HOX antisense intergenic RNA (HOTAIR) (11). HOTAIR is expressed by the homeobox C gene (HOXC) locus and is located in the HOXC cluster between the HOXC11 and HOXC12 genes on human chromosome $12 q 13.13$ (12). Increasing evidence suggests that HOTAIR is strongly associated with different types of cancer (13) (Fig. 1). For example, HOTAIR plays a role in metastasis progression through canonical and noncanonical pathways in breast carcinoma, hepatocellular carcinoma (HCC), lung carcinoma, gastric carcinoma and oral squamous cell carcinoma (14-18) (Table I). In addition, HOTAIR participates in regulating cell cycle progression, tumour proliferation, epithelial-to-mesenchymal transition (EMT) and tumour migration and invasion by altering gene expression (19). 
According to a recent study, HOTAIR promotes tumour metastasis in several ways, including: i) Inhibition by competing with miRNAs, downregulating the expression levels of EMT-related proteins, ii) controlling angiogenesis to provide tumour tissue with the oxygen and nutrients necessary for metabolism, iii) promoting tumour progression by regulating the expression of genes associated with cell metabolism; iv) controlling gene silencing to regulate tumour metastasis and v) playing a role in cargo loading, such as in exosomes, to promote tumour cell metastasis (Fig. 2).

The present review discusses the pathways and molecular mechanisms of HOTAIR in tumour metastasis, emphasizes the function of HOTAIR in human malignant tumour metastasis, and provides a foundation for its application in tumour diagnosis, prognosis and medical treatment of various tumours.

\section{TGF- $\beta$ pathway}

The EMT is the process of epithelial cell transformation or transdifferentiation from the epithelial to the mesenchymal cell type (20). In this process, cells lose their epithelial properties and can migrate, breaking away from the epithelial cell colony and moving to surrounding and distant tissues (20). The EMT and mesenchymal-to-epithelial transformation (MET) processes are crucial during embryonic development (organogenesis and regeneration), and are triggered during tumour invasion and metastasis (21).

The transforming growth factor $\beta$ (TGF- $\beta$ ) signalling pathway comprises a series of signal transmission processes mediated by transforming growth factor. In humans, it includes the TGF $\beta$ subtype, bone morphogenetic protein, activin, and growth and differentiation factor, which has an indispensable effect on cell proliferation and metastasis (22). TGF- $\beta$ regulates the EMT primarily through a group of transcription factors, including the basic helix-loop-helix proteins Twist and E47, zinc finger proteins Snail and Slug (also called Snail2), and zinc finger and homeodomain proteins ZEB1, ZEB2 (23), and FOXC2 (24), which inhibit E-cadherin expression (a key process in the EMT), and the expression levels of other epithelial markers. E-cadherin is a transmembrane glycoprotein that connects epithelial cells together at adhesion junctions and is closely associated with the EMT (25). E-cadherin exerts its tumour-suppressing role primarily by sequestering $\beta$-catenin, preventing its binding to lymphoid enhancer factor/T cell factor (26). Increasing evidence suggests that HOTAIR is associated with the EMT process through regulation of the TGF- $\beta$ pathway. The molecular mechanism occurs mainly through two processes. On one hand, HOTAIR regulates the expression of key EMT-related genes, such as E-cadherin, $\mathrm{N}$-cadherin and Snail, to promote tumour metastasis by acting as a competitive endogenous RNA (ceRNA) that competes with a miRNA for binding sites on mRNA (13). On the other hand, HOTAIR promotes gene transcription, and thus regulates gene expression, controlling the EMT through epigenetic mechanisms $(19,27)$.

$\mathrm{Wu}$ et al (28) demonstrated that silencing HOTAIR improves the capability of LoVo colon cancer cells to invade, proliferate and migrate, and promotes their apoptosis by inhibiting the EMT. In addition, Dasgupta et al (29) reported that the miR-203-HOTAIR interaction suppresses metastatic genes, such as those for E-cadherin and claudin, regulating the EMT and metastasis in renal cell carcinoma (RCC). Furthermore, downregulation of HOTAIR significantly decreases the migration and expression levels of the epithelial markers, Vimentin and Snail, that are induced by TGF- $\beta 1$, while E-cadherin expression markedly increases, which promotes RCC cell migration, proliferation and the EMT through negative modulation of miR-217 (30). For miR-217, HOTAIR plays a ceRNA role and modulates HIF-1a expression by sponging miR-217 to promote the EMT through the miR-217/HIF-1a/AXL axis (30). Similarly, HOTAIR represses miR-7 expression, resulting in upregulated SETDB1 expression in stem cells of breast cancer, which promotes the EMT (31). There is also evidence to suggest that HOTAIR has an important effect on the proliferation, invasion and migration of liver tumour cells and the EMT by sponging miR-217-5p (32).

In addition to acting as a ceRNA, HOTAIR can also drive EMT through epigenetic mechanisms, according to recent studies. For example, HOTAIR specifically regulates HOXC8 expression and changes protein levels associated with cell proliferative, invasive and migratory abilities, promoting the invasion and pervasion of oesophageal cancer cells (33). Wu et al (34) demonstrated that HOTAIR is highly expressed in oral squamous cell carcinoma (OSCC) with regional lymph node metastasis (N1) compared with OSCC without N1. It was also reported that HOTAIR inhibits E-cadherin expression by associating with enhancer of zeste homolog 2 (EZH2) and $\mathrm{H} 3 \mathrm{~K} 27 \mathrm{me} 3$, improving the metastatic and invasive capacities of OSCC cells, and promoting EMT (34). Notably, the progression and migration of breast cancer is also regulated by the TGF- $\beta 1 /$ HOTAIR axis (35). Secretion of TGF- $\beta 1$ by CAF activates the TGF- $\beta 1 /$ Smad pathway in breast cancer cells, increasing HOTAIR transcription and modifying histones in the CDK5 signalling pathway, which leads to changes in the tumour microenvironment (35). In gastric cancer, HOTAIR negatively regulates E-cadherin mRNA and protein expression levels (36). In addition, HOTAIR inhibits E-cadherin expression by acetylating histone H3K27 to methylate the E-cadherin promoter, thereby promoting EMT (36). Liu et al (37) demonstrated that HOTAIR and its two fragments, HOTAIR 3' and HOTAIR 5', promote cell proliferation of non-small cell lung cancer (NSCLC) in the $G_{1} / S$ phase by restricting the cell cycle through the regulation of the $\mathrm{Rb}-\mathrm{E} 2 \mathrm{~F}$ pathway in vitro and through the EMT pathway, which affects cancer metastasis and invasion. Liu et al (38) reported that HOTAIR recruitment and combination with polycomb repressive complex 2 (PRC2) epigenetically inhibits the control target C-Met (HGF/C-Met/Snail pathway) and miR-34a associated with Snail, thus promoting the procession of the GC cell EMT and acceleration of tumour migration. HOTAIR plays a key role in cervical cancer cell metastasis and invasive as transfection with si-HOTAIR increases E-cadherin expression and decreases the EMT transcription factors, Snail and Twist (39). Berrondo et al (40) demonstrated that lack of HOTAIR expression in urothelial bladder cancer (UBC) cell lines regulates the expression levels of genes associated with EMT, including SNAI1, TWIST1, ZEB1, ZO1, LAMB3, matrix metalloproteinase (MMP)1 and LAMC2, to decrease migration and invasion. 
Table I. Expression and signalling pathways associated with tumour metastasis of HOTAIR.

\begin{tabular}{|c|c|c|c|c|}
\hline Cancer type & Expression & Pathways & Molecules & Refs. \\
\hline Breast cancer & Up & TGF- $\beta$, PI3K/AKT & miR-7, TGF- $\beta 1$, p53 & $(27,31,35,58,60)$ \\
\hline Lung cancer & Up & TGF- $\beta$, VEGF & EMT, MMP-2, MMP-9 & $(37,72,79)$ \\
\hline Liver cancer & Up & TGF- $\beta, \mathrm{Wnt} / \beta, \mathrm{VEGF}$ & $\begin{array}{l}\text { miR-217-5p, EMT, MMP-9, } \\
\text { RBM38 }\end{array}$ & $(32,44,71)$ \\
\hline Colorectal cancer & Up & $\begin{array}{l}\text { TGF- } \beta, \text { Wnt } / \beta \\
\text { PI3K/AKT }\end{array}$ & $\begin{array}{l}\text { EMT, miR-326, } \\
\text { miR-203a-3p, IGF2BP2 }\end{array}$ & $(28,47,61)$ \\
\hline ESCC & Up & $\mathrm{Wnt} / \beta$ & WIF-1 & $(50)$ \\
\hline Renal cancer & Up & TGF- $\beta$, PI3K/AKT & $\begin{array}{l}\text { miR-203, claudin, E-cadherin, } \\
\text { PTEN, miR-217 }\end{array}$ & $(29,30)$ \\
\hline Gastric cancer & Up & $\mathrm{Wnt} / \beta, \mathrm{PI} 3 \mathrm{~K} / \mathrm{AKT}$ & E-cadherin, miR-34a & $(36,38,46)$ \\
\hline Esophageal cancer & Up & & miR-204 & (33) \\
\hline OSCC & Up & TGF- $\beta$ & E-cadherin & $(34)$ \\
\hline HNSCC & Up & PI3K/AKT, VEGF & miR-206, MMP-9 & $(64,74)$ \\
\hline Cervical cancer & Up & & E-cadherin & (39) \\
\hline Bladder cancer & Up & & EMT & $(40)$ \\
\hline Ovarian cancer & Up & $\mathrm{Wnt} / \beta$ & & $(49)$ \\
\hline Leukemia & Up & $\mathrm{Wnt} / \beta, \mathrm{PI} 3 \mathrm{~K} / \mathrm{AKT}$ & $\begin{array}{l}\text { Cyclin D1, GSK-3 } \beta, \text { c-Myc, } \\
\text { miR-143 }\end{array}$ & $(48,62)$ \\
\hline Osteosarcoma & Up & PI3K/AKT, VEGF & $\begin{array}{l}\text { E-cadherin, N-cadherin, } \\
\text { p-mTOR, p-PI3K, pAKT, } \\
\text { p27, MMP-9, MMP-2 }\end{array}$ & $(59)$ \\
\hline Melanoma & Up & PI3K/AKT & miR-152-3p & $(47)$ \\
\hline Glioma & Up & PI3K/AKT, VEGF & $\begin{array}{l}\text { miR-206, FGF-1, MMP-9, } \\
\text { MMP-7 }\end{array}$ & $(66,73)$ \\
\hline
\end{tabular}

ESCC, esophageal squamous cell carcinoma; OSCC, oral squamous cell carcinoma; HNSCC, head and neck squamous cell carcinoma; TGF $\beta$, transforming growth factor $\beta$; VEGF, vascular endothelial growth factor; miR, microRNA; EMT, epithelial-to-mesenchymal transition; MMP, matrix metalloproteinase.

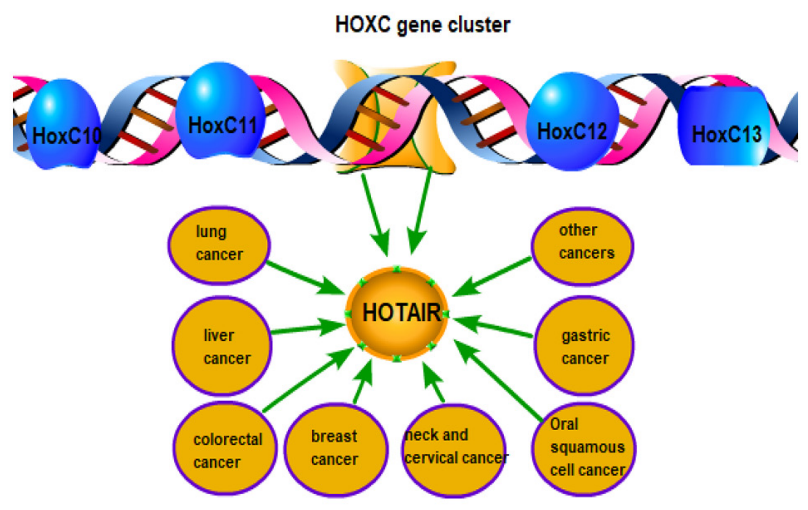

Figure 1. Structure and location of 1ncRNA HOTAIR, and its association with different types of human cancer. The HOTAIR gene is in the HOXC gene cluster, specifically between HoxC11 and HoxC12. HOTAIR is associated with the occurrence and development of human cancer. IncRNA, long non-coding RNA; HOTAIR, HOX antisense intergenic RNA.

TGF- $\beta$ promotes EMT through transcription and post-transcriptional adjustment of a set of transcription elements that inhibit epithelial characteristics, including cell junctions and the expression of polar complex components, and enhancing mesenchymal characteristics (41). As a key

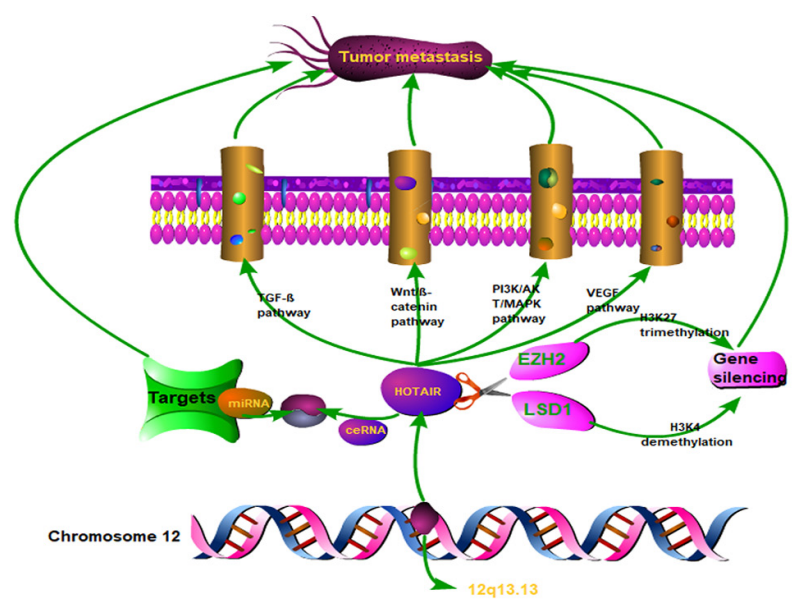

Figure 2. Overview of HOTAIR and tumour metastasis. This figure illustrates the chromosome where HOTAIR is located, summarizes the functions and molecular mechanisms of HOTAIR-mediated gene silencing, association between HOTAIR and miRNA, and four associated signalling pathways. These include: i) Act as a ceRNA to compete with miRNA, ii) regulate gene silencing by $\mathrm{H} 3 \mathrm{~K} 27$ trimethylation and $\mathrm{H} 3 \mathrm{~K} 4$ demethylation and iii) promote metastasis through influence on the TGF- $\beta$, Wnt $/ \beta$-catenin, PI3K/AKT/MAPK and VEGF pathways. HOTAIR, HOX antisense intergenic RNA; miRNA, microRNA; ceRNA, competitive endogenous RNA; TGF $\beta$, transforming growth factor $\beta$; VEGF, vascular endothelial growth factor; EZH2, enhancer of zeste homolog 2. 
factor triggering tumour promotion, HOTAIR enhances invasiveness and metastatic ability by inducing EMT through both ceRNAs and epigenetic mechanisms in the tumour microenvironment (19).

\section{Wnt/ $\beta$-catenin pathway}

The Wnt/ $\beta$-catenin pathway plays a pivotal role in regulating cellular processes and angiogenesis in tumours, affecting oncogenic processes (42). Owing to genic and epigenetic alterations, abnormal activation of $\mathrm{Wnt} / \beta$-catenin signalling is associated with different types of tumours, such as ovarian cancer and liver cancer (43). HOTAIR activates the $\mathrm{Wnt} / \beta$-catenin signalling pathway to promote tumour progression (15).

As early as 2016, it was demonstrated that HOTAIR is highly expressed in liver cancer tissues compared with adjacent normal tissues, and its expression is significantly associated with poor tumour metastasis (44). Overexpression of HOTAIR partially promotes HCC processes by activating the Wnt/ $\beta$-catenin signalling pathway, and regulating the proliferation, invasion and tumorigenic ability of liver cancer cells in vivo (44). HOTAIR has also been reported to specifically act in HeLa cells, playing an indispensable role in their proliferation, migration and invasion, as HOTAIR participates in downregulating TET1 expression to promote the activity of Wnt/ $\beta$-catenin signalling (45). The primary effect is to increase the methylation pattern and decrease the expression levels of SOX17, PCDH10, AJAP1 and MAGI2 genes (38). Cheng et al (46) demonstrated that miR-34a in Wnt/ $\beta$-catenin signalling regulates HOTAIR in GC tissues and cell lines, which promotes tumour growth in vivo. It has also been reported that HOTAIR gene knockdown is negatively associated with the overexpression of miR-203a-3p, which affects cell proliferation and metastasis (47). miR-203a-3p targets $\beta$-catenin and GRG5, while overexpression of miR-203a-3p and HOTAIR knockdown suppress Wnt/ $\beta$-catenin signalling (47). In addition, overexpression of HOTAIR activates Wnt/ $\beta$-catenin, which increases cyclin D1, GSK-3 $\beta$ and c-Myc expression, as well as enhancing survival and the proliferation of leukaemia cells (48). Furthermore, cell cycle progression is promoted by overexpression of HOTAIR through activation of Wnt/ $\beta$-catenin signalling, which in turn promotes ovarian cancer cell proliferation and invasion (49). HOTAIR directly controls WIF-1 expression by promoting the methylation of its histone $\mathrm{H} 3 \mathrm{~K} 27$ in the promoter region (50). Wnt/ $\beta$-catenin signalling is triggered by suppressing WIF-1, thereby promoting tumour invasion and migration (50). Aberrant activation of $\mathrm{Wnt} / \beta$-catenin signalling, generally caused by genetic and epigenetic alterations, is associated with a few types of tumour migration (51). The combination of HOTAIR expression and genetic alterations may decreases $\mathrm{Wnt} / \beta$-catenin signalling activity and increase the mRNA levels of its negative regulators (45).

\section{PI3K/AKT/MAPK pathway}

PI3K/Akt signalling is associated with cell proliferation, apoptosis and metastasis $(52,53)$. HOTAIR plays an important role in tumour metastasis in this pathway by affecting the expression of related upstream and downstream genes (54).
According to Dasgupta et al (29), overexpression of miR-203 supresses HOTAIR, resulting in upregulated PTEN expression, a main regulator of the PI3K/Akt pathway (55). miR-203 mimic mediated induction of PTEN resulted in the induction of p21 in ACHN and Caki-1 cells $(56,57)$ and upregulated mRNA and protein expression levels of the downstream molecule, p21, which induces the PTEN gene and suppresses the effectors of downstream pathways that control proliferation and metastasis. Cheng et al (46) also indicated that the PI3K/Akt signalling pathway is regulated by HOTAIR through miR-34a, which promotes tumour growth. In addition, Yu et al (58) demonstrated that HOTAIR knockdown in MCF-7 cells increases p53 expression and decreases AKT and JNK expression, resulting in decreased cell migration and invasion. HOTAIR silencing decreases the expression levels of $\mathrm{p}$-mTOR, p-PI3K and p-AKT, thus, HOTAIR promotes osteosarcoma cell proliferation by activating AKT/mTOR signalling (59). In addition, HOTAIR knockdown restrains the proliferation and metastasis of breast cancer cells by decreasing the phosphorylation of PI3K/AKT/mTOR (60). Pan et al (61) reported that the HOTAIR/miR-326/FUT6 axis regulates the fucosylation of CD44 to facilitate colorectal cancer progression through the PI3K/AKT/mTOR pathway. Both HOTAIR inhibition and overexpression of miR-143 inhibit the proliferation and promote the apoptosis of chronic leukaemia KCL22 and K562 cells through changes to PI3K/AKT pathway proteins (62). HOTAIR functions as a ceRNA, competing with miR-152-3p to release c-MET mRNA. This leads to downstream $\mathrm{PI} 3 \mathrm{~K} / \mathrm{Akt} / \mathrm{mTOR}$ signalling pathway activation, and melanoma cell proliferation and metastasis (63). It is speculated that HOTAIR competitively binds to miR-206 and restrains its expression. miR-206 targets STC2 to inhibit head and neck squamous cell cancer (HNSCC) cell proliferation, migration and invasion through the PI3K/Akt signalling pathway (64). Thus, HOTAIR silencing inhibits the proliferation, migration and invasion of HNSCC cells, while increasing their rate of apoptosis. Fibroblast growth factor-1 (FGF1) belongs to the fibroblast family and activates the PI3K/AKT and MEK1/2 signalling pathways $(65,66)$. HOTAIR inhibits FGF1 expression by upregulating miR-326 expression, which inhibits the proliferation, invasion and migration of cells in the $G_{0} / G_{1}$ phase, promotes apoptosis and induces cell cycle arrest (66).

Taken together, these results suggest that the PI3K/Akt/ MAPK signalling pathway is significant for the transduction of membrane receptor signals into cells, which functions in tumour metastasis by influencing tumour cell migration and adhesion, as well as tumour cell angiogenesis.

\section{Vascular endothelial growth factor (VEGF) pathway}

It is well-known that tumour angiogenesis plays an important role in tumour invasion and migration. Among angiogenesis factors, VEGF, a highly specific vascular endothelial growth factor, plays a vital role in the extracellular matrix and vascular endothelial cells (67). HOTAIR is directly involved in promoting VEGFA transcription. The results of a dual-luciferase report assay revealed that the transcription of the $2.3 \mathrm{~kb}$ VEGFA promoter is activated by HOTAIR (68). The degradation of extracellular matrix proteins is closely associated with MMPs, increasing the potential of cancer cells 
to invade, proliferate and migrate (69). In addition, glucose regulatory protein 78 , a member of the heat shock protein 70 family, has been recognized as an anti-angiogenic target of HOTAIR in NPC cells $(68,70)$. A previous study hypothesized that HOTAIR knockdown decreases proliferation of cells and is associated with decreased MMP-9 and VEGF expression, which play vital roles in the motility and migration of cells in HCC (71). Liu et al (72) demonstrated that HOTAIR is upregulated in NSCLC tissues, which promotes cell invasion and migration, partially through the downregulation of HOXA5; in addition, HOTAIR knockdown decreases MMP-2 and MMP-9 protein expression levels in NSCLC cells. Collectively, these results suggest that HOTAIR may affect the potential of NSCLC cells to invade and migrate by altering the expression levels of MMPs and HOXA5 (72). In addition, Zhao et al (73) assessed 123 patients undergoing surgery for glioma and demonstrated that HOTAIR may facilitate invasion by increasing the expression levels of MMP-9, MMP-7 and VEGF. Kim et al reported that HOTAIR accelerates the invasiveness of cervical cancer cells by upregulating VEGF and MMP-9 expression (74). HOTAIR expression is significantly upregulated in patients with osteosarcoma (OS), and is associated with lymph node metastasis (59). In addition, HOTAIR mediates the proliferation of OS cells by regulating the expression levels of cyclin E, CDK2, CDK4 and p27, MMP-2, MMP-9 and CD44, which promotes OS cell invasion and metastasis (59). Taken together, these results suggest that HOTAIR promotes tumour cell metastasis by regulating VEGF-related specific proteins, such as extracellular matrix proteins; however, the specific molecular mechanisms are yet to be investigated.

\section{Others}

Epigenetic modification is defined as heritable changes that appear in gene expression of unchanged DNA sequences. In addition, chromatin remodelling is an important part of epigenetics (75). A single lncRNA can serve as the interface of DNA and specific chromatin remodelling activities, leading to diseases, such as cancer and activities, such as tumour metastasis (76-78).

HOTAIR acts as a molecular scaffold to connect and target PRC2 and LSD1, histone modification complexes, and subsequently reprograms chromatin states by coupling histone H3K27 methylation and H3K4 demethylation to promote cancer metastasis through epigenetic gene silencing (27). Gupta et al (27) proposed that enforced expression of HOTAIR in epithelial cancer cells induced genome-wide re-targeting of PRC2 to an occupancy pattern more resembling embryonic fibroblasts, leading to altered histone $\mathrm{H} 3$ lysine 27 methylation, gene expression, and increased cancer invasiveness and metastasis in a manner dependent on PRC2. Recently, Wu et al (28) reported that proliferation, invasion and metastasis can be inhibited by silencing HOTAIR, and the apoptosis of LoVo colon cancer cells can be expedited by supressing IGF2BP2. In addition, protein modification plays an indispensable role in epigenetic modifications. HOTAIR functions in the promotion of the migration and invasion of HCC cells by inhibiting RBM38, an RNA-binding protein, suggesting that HOTAIR and RBM38 play significant roles in the progression of
HCC (79). Notably, RBM38 may have an important function in the TGF- $\beta$ signalling pathway, according to an integrated KEGG pathway analysis; however, further studies are required to confirm these findings.

Increasing evidence suggests that cancer cells support tumour progression by secreting extracellular vesicles (EVs), and several lncRNAs appear in EVs in different tumour cells (80). IncRNAs from exosomes act as signalling molecules for intercellular communication, and play indispensable roles in tumour invasion and metastasis, including HOTAIR (81). The expression levels of SNAI1, TWIST1, MMP1, LAMB3, ZEB1, ZO-1, JAM2, LAMC2 and ABL2 in UBC cells are changed by exosomal lncRNA-HOTAIR, which induces the migration and invasion of carcinoma cells (40). It has been demonstrated that HOTAIR originating from carcinoma cells exhibits the possibility of being liberated in the tumor microenvironment by EVs and delivered to endothelium cells, thereby accelerating tumour metastasis $(82,83)$. Although the specific association between exosomal HOTAIR and cancer metastasis remains unclear, the role of HOTAIR is worthy of further investigation.

\section{Prospects and challenges}

Tumour metastasis refers to tumour cells leaving their primary growth sites (local infiltration and intravascular infiltration), undergoing systemic displacement (surviving in the circulation, retention in distant organs and extravasation), and adapting for survival and reproduction in the foreign microenvironment of distant tissues (84). With the development of medical technology, surgical resection and adjuvant therapy can cure limited primary tumours; however, metastatic diseases remain largely incurable. This explains why $>90 \%$ of cancer mortality is attributed to metastasis instead of the primary tumours caused by these malignant lesions (85).

HOTAIR is abundant in saliva, clinical blood samples and exosomes. Owing to its structural stability and cell/tissue type specificity, HOTAIR is stable, sensitive, specific and easy to detect $(40,86)$. Early detection of HOTAIR in body fluid samples may facilitate its role as a biomarker for the diagnosis of different types of carcinomas (87). A previous study demonstrated that serum exosomes containing HOTAIR act as potential diagnostic and prognostic biomarkers for breast cancer, and its high expression is associated with response to treatment (88). In addition, Wang et al (89) demonstrated that HOTAIR is significantly associated with clinical parameters of laryngeal squamous cell carcinoma (LSCC), suggesting its potential as a valuable biomarker for screening LSCC and a promising predictive tool for patients with LSCC patients. Similar results have been reported in lung cancer, stomach cancer and liver cancer (90-93). In summary, HOTAIR functions as follows: i) Promotes epigenetic activation/repression of tumour suppressor gene function, ii) affects the inhibition of target gene expression by competitively binding miRNA and iii) modifies genes to ensure their compatibility with transcription factors, while ribosomes can post-transcriptionally interact with splicing factors (30).

The complexity of the molecular mechanism of HOTAIR was unexpected; thus, more detailed studies are required. It is speculated that a better understanding of the biological functions of HOTAIR in cancer pathogenesis will provide in-depth knowledge about malignant tumours, and help identify basic 
disease processes and provide useful treatment for patients who suffer from tumours. In addition, investigations to elucidate the molecular mechanisms of how HOTAIR is expressed and regulated, such as the characteristics of HOTAIR protein biochemistry and structure and HOTAIR-DNA interactions, may help identify potential therapeutic treatment tactics for different types of cancer.

\section{Acknowledgements}

Not applicable.

\section{Funding}

The present study was supported by the National Natural Science Foundation of China (grant no. 81904129), the National Natural Science Foundation of China (grant no. 81904129), the Shanghai Pudong New Area Health Commission's 2019 Joint Public Relations Project (grant no. PW2019D-7), the three-year action plan (grant no. 2018-2020) for further accelerating the development of Chinese medicine in Shanghai (grant no. ZY(2018-2020)-ZYBZ-01) and the 2019 Shanghai Chinese and Western Medicine Clinical Collaboration Pilot Project Funding (grant no. ZXYXZ-201909).

\section{Availability of data and materials}

All data generated or analyzed during this study are included in this published article.

\section{Authors' contributions}

LC conceived this review, searched, analyzed and drafted the initial manuscript. XQ and ZW participated in discussing, collecting literature and revising the manuscript for important intellectual details. XZ conceived and revised the manuscript for important intellectual details. All authors have read and approved the final manuscript.

\section{Ethics approval and consent to participate}

Not applicable.

\section{Patient consent for publication}

Not applicable.

\section{Competing interests}

The authors declare that they have no competing interests.

\section{References}

1. Ferlay J, Soerjomataram I, Dikshit R, Eser S, Mathers C, Rebelo M, Parkin DM, Forman D and Bray F: Cancer incidence and mortality worldwide: Sources, methods and major patterns in GLOBOCAN 2012. Int J Cancer 136: E359-E386, 2015.

2. Dušek L, Mužík J, Malúšková D, Májek O, Pavlík T, Koptíková J, Gregor J, Brabec P and Abrahámová J: Epidemiology of screening-targeted cancers according to new data of the Czech national cancer registry. Klin Onkol 27 (Suppl 2): S19-S39, 2014 (In Czech).
3. Rosenberg AR, Kroon L, Chen L, Li CI and Jones B: Insurance status and risk of cancer mortality among adolescents and young adults. Cancer 121: 1279-1286, 2015

4. Van der Weyden L, Arends MJ, Rust AG, Poulogiannis G, McIntyre RE and Adams DJ: Increased tumorigenesis associated with loss of the tumor suppressor gene Cadm1. Mol Cancer 11: 29, 2012.

5. Chan XH, Nama S, Gopal F, Rizk P, Ramasamy S, Sundaram G, Ow GS, Ivshina AV, Tanavde V, Haybaeck J, et al: Targeting glioma stem cells by functional inhibition of a prosurvival oncomiR-138 in malignant gliomas. Cell Rep 2: 591-602, 2012.

6. Shroff EH, Eberlin LS, Dang VM, Gouw AM, Gabay M, Adam SJ, Bellovin DI, Tran PT, Philbrick WM, Garcia-Ocana A, et al: MYC oncogene overexpression drives renal cell carcinoma in a mouse model through glutamine metabolism. Proc Natl Acad Sci USA 112: 6539-6544, 2015.

7. Zhang J, Zhang P, Wang L, Piao HL and Ma L: Long non-coding RNA HOTAIR in carcinogenesis and metastasis. Acta Biochim Biophys Sin (Shanghai) 46: 1-5, 2014.

8. Baek D, Villén J, Shin C, Camargo FD, Gygi SP and Bartel DP: The impact of microRNAs on protein output. Nature 455: 64-71, 2008.

9. Selbach M, Schwanhäusser B, Thierfelder N, Fang Z, Khanin R and Rajewsky N: Widespread changes in protein synthesis induced by microRNAs. Nature 455: 58-63, 2008.

10. Bushati N and Cohen SM: microRNA functions. Annu Rev Cell Dev Biol 23: 175-205, 2007.

11. Memczak S, Jens M, Elefsinioti A, Torti F, Krueger J, Rybak A, Maier L, Mackowiak SD, Gregersen LH, Munschauer M, et al: Circular RNAs are a large class of animal RNAs with regulatory potency. Nature 495: 333-338, 2013.

12. Wan Y and Chang HY: HOTAIR: Flight of noncoding RNAs in cancer metastasis. Cell Cycle 9: 3391-3392, 2010.

13. Hao Y, Baker D and Ten Dijke P: TGF- $\beta$-mediated epithelial-mesenchymal transition and cancer metastasis. Int J Mol Sci 20: 2767, 2019.

14. Qin W, Kang P, Xu Y, Leng K, Li Z, Huang L, Gao J, Cui Y and Zhong X: Long non-coding RNA HOTAIR promotes tumorigenesis and forecasts a poor prognosis in cholangiocarcinoma. Sci Rep 8: 12176, 2018.

15. Li J, Tian H, Yang J and Gong Z: Long noncoding RNAs regulate cell growth, proliferation, and apoptosis. DNA Cell Biol 35: 459-470, 2016.

16. Rossi MN and Antonangeli F: LncRNAs: New players in apoptosis control. Int J Cell Biol 2014: 473857, 2014

17. Zhou S, He Y, Yang S, Hu J, Zhang Q, Chen W, Xu H, Zhang H, Zhong S, Zhao J and Tang J: The regulatory roles of IncRNAs in the process of breast cancer invasion and metastasis. Biosci Rep 38: BSR20180772, 2018.

18. Zhou T, Ding JW, Wang XA and Zheng XX: Long noncoding RNAs and atherosclerosis. Atherosclerosis 248: 51-61, 2016.

19. Bhan A and Mandal SS: LncRNA HOTAIR: A master regulator of chromatin dynamics and cancer. Biochim Biophys Acta 1856: 151-164, 2015.

20. Nieto MA: The ins and outs of the epithelial to mesenchymal transition in health and disease. Annu Rev Cell Dev Biol 27: 347-376, 2011.

21. Skrypek N, Goossens S, De Smedt E, Vandamme N and Berx G: Epithelial-to-mesenchymal transition: Epigenetic reprogramming driving cellular plasticity. Trends Genet 33: 943-959, 2017.

22. Syed V: TGF- $\beta$ signaling in cancer. J Cell Biochem 117: 1279-1287, 2016.

23. Peinado H, Olmeda D and Cano A: Snail, Zeb and bHLH factors in tumour progression: An alliance against the epithelial phenotype? Nat Rev Cancer 7: 415-428, 2007.

24. Mani SA, Yang J, Brooks M, Schwaninger G, Zhou A, Miura N, Kutok JL, Hartwell K, Richardson AL and Weinberg RA: Mesenchyme forkhead 1 (FOXC2) plays a key role in metastasis and is associated with aggressive basal-like breast cancers. Proc Natl Acad Sci USA 104: 10069-10074, 2007.

25. David CJ, Huang YH, Chen M, Su J, Zou Y, Bardeesy N, Iacobuzio-Donahue CA and Massagué J: TGF- $\beta$ tumor suppression through a lethal EMT. Cell 164: 1015-1030, 2016.

26. Wong SHM, Fang CM, Chuah LH, Leong CO and Ngai SC: E-cadherin: Its dysregulation in carcinogenesis and clinical implications. Crit Rev Oncol Hematol 121: 11-22, 2018.

27. Gupta RA, Shah N, Wang KC, Kim J, Horlings HM, Wong DJ, Tsai MC, Hung T, Argani P, Rinn JL, et al: Long non-coding RNA HOTAIR reprograms chromatin state to promote cancer metastasis. Nature 464: 1071-1076, 2010. 
28. Wu XL, Lu RY, Wang LK, Wang YY, Dai YJ, Wang CY, Yang YJ, Guo F, Xue J and Yang DD: Long noncoding RNA HOTAIR silencing inhibits invasion and proliferation of human colon cancer LoVo cells via regulating IGF2BP2. J Cell Biochem: Oct 18, 2018 (Epub ahead of print).

29. Dasgupta P, Kulkarni P, Majid S, Shahryari V, Hashimoto Y, Bhat NS, Shiina M, Deng G, Saini S, Tabatabai ZL, et al: MicroRNA-203 inhibits long noncoding RNA HOTAIR and regulates tumorigenesis through epithelial-to-mesenchymal transition pathway in renal cell carcinoma. Mol Cancer Ther 17: 1061-1069, 2018

30. Hong Q, Li O, Zheng W, Xiao WZ, Zhang L, Wu D, Cai GY, He JC and Chen XM: LncRNA HOTAIR regulates HIF-1 $\alpha /$ AXL signaling through inhibition of miR-217 in renal cell carcinoma. Cell Death Dis 8: e2772, 2017.

31. Zhang H, Cai K, Wang J, Wang X, Cheng K, Shi F, Jiang L, Zhang Y and Dou J: MiR-7, inhibited indirectly by lincRNA HOTAIR, directly inhibits SETDB1 and reverses the EMT of breast cancer stem cells by downregulating the STAT3 pathway. Stem Cells 32: 2858-2868, 2014.

32. Gong $X$ and Zhu Z: Long noncoding RNA HOTAIR contributes to progression in hepatocellular carcinoma by sponging miR-217-5p. Cancer Biother Radiopharm 35: 387-396, 2020.

33. Wang AH, Tan P, Zhuang Y, Zhang XT, Yu ZB and Li LN Down-regulation of long non-coding RNA HOTAIR inhibits invasion and migration of oesophageal cancer cells via up-regulation of microRNA-204. J Cell Mol Med 23: 6595-6610, 2019.

34. Wu Y, Zhang L, Zhang L, Wang Y, Li H, Ren X, Wei F, Yu W, Liu T, Wang X, et al: Long non-coding RNA HOTAIR promotes tumor cell invasion and metastasis by recruiting EZH2 and repressing E-cadherin in oral squamous cell carcinoma. Int J Oncol 46: 2586-2594, 2015.

35. Ren Y, Jia HH, Xu YQ, Zhou X, Zhao XH, Wang YF, Song X, Zhu ZY, Sun T, Dou Y, et al: Paracrine and epigenetic control of CAF-induced metastasis: The role of HOTAIR stimulated by TGF-ß1 secretion. Mol Cancer 17: 5, 2018.

36. Song Y, Wang R, Li LW, Liu X, Wang YF, Wang QX and Zhang Q: Long non-coding RNA HOTAIR mediates the switching of histone $\mathrm{H} 3$ lysine 27 acetylation to methylation to promote epithelial-to-mesenchymal transition in gastric cancer. Int J Oncol 54: 77-86, 2019.

37. Liu M, Zhang H, Li Y, Wang R, Li Y, Zhang H, Ren D, Liu H, Kang C and Chen J: HOTAIR, a long noncoding RNA, is a marker of abnormal cell cycle regulation in lung cancer. Cancer Sci 109: 2717-2733, 2018

38. Liu YW, Sun M, Xia R, Zhang EB, Liu XH, Zhang ZH, Xu TP, De W, Liu BR and Wang ZX: LincHOTAIR epigenetically silences miR34a by binding to PRC2 to promote the epithelial-to-mesenchymal transition in human gastric cancer. Cell Death Dis 6: e1802,2015.

39. Kim HJ, Yim GW, Baek SM, Kim JW and Kim YT: Long noncoding RNA HOTAIR is associated with human cervical cancer progression. Gynecol Oncol 133 (Suppl 1): S5, 2014

40. Berrondo C, Flax J, Kucherov V, Siebert A, Osinski T, Rosenberg A, Fucile C, Richheimer S and Beckham CJ: Expression of the long non-coding RNA HOTAIR correlates with disease progression in bladder cancer and is contained in bladder cancer patient urinary exosomes. PLoS One 11 : e0147236, 2016

41. Heldin $\mathrm{CH}$, Vanlandewijck $\mathrm{M}$ and Moustakas A: Regulation of EMT by TGF $\beta$ in cancer. FEBS Lett 586: 1959-1970, 2012.

42. Clevers $\mathrm{H}$ and Nusse R: Wnt/ $\beta$-catenin signaling and disease. Cell 149: 1192-1205, 2012

43. Ochoa-Hernández AB, Juárez-Vázquez CI, Rosales-Reynoso MA and Barros-Núñez P: WNT- $\beta$-catenin signaling pathway and its relationship with cancer. Cir Cir 80: 389-398, 2012 (In Spanish).

44. Gao JZ, Li J, Du JL and Li XL: Long non-coding RNA HOTAIR is a marker for hepatocellular carcinoma progression and tumor recurrence. Oncol Lett 11: 1791-1798, 2016.

45. Salmerón-Bárcenas EG, Illades-Aguiar B, Del MoralHernández O, Ortega-Soto A and Hernández-Sotelo D: HOTAIR knockdown decreased the activity $\mathrm{Wnt} / \beta$-catenin signaling pathway and increased the mRNA levels of its negative regulators in Hela cells. Cell Physiol Biochem 53: 948-960, 2019.

46. Cheng C, Qin Y, Zhi Q, Wang J and Qin C: Knockdown of long non-coding RNA HOTAIR inhibits cisplatin resistance of gastric cancer cells through inhibiting the PI3K/Akt and Wnt/ $\beta$-catenin signaling pathways by up-regulating miR-34a. Int J Biol Macromol 107: 2620-2629, 2018.
47. Xiao Z, Qu Z, Chen Z, Fang Z, Zhou K, Huang Z, Guo X and Zhang Y: LncRNA HOTAIR is a prognostic biomarker for the proliferation and chemoresistance of colorectal cancer via MiR-203a-3p-mediated Wnt/ $\beta$-catenin signaling pathway. Cell Physiol Biochem 46: 1275-1285, 2018.

48. Li GJ, Ding H and Miao D: Long-noncoding RNA HOTAIR inhibits immunologic rejection of mouse leukemia cells through activating the Wnt/ $\beta$-catenin signaling pathway in a mouse model of leukemia. J Cell Physiol 234: 10386-10396, 2019.

49. Li J, Yang S, Su N, Wang Y, Yu J, Qiu H and He X: Overexpression of long non-coding RNA HOTAIR leads to chemoresistance by activating the Wnt/ $\beta$-catenin pathway in human ovarian cancer. Tumour Biol 37: 2057-2065, 2016.

50. Ge XS, Ma HJ, Zheng XH, Ruan HL, Liao XY, Xue WQ, Chen YB, Zhang Y and Jia WH: HOTAIR, a prognostic factor in esophageal squamous cell carcinoma, inhibits WIF-1 expression and activates Wnt pathway. Cancer Sci 104: 1675-1682, 2013.

51. Ying Y and Tao Q: Epigenetic disruption of the WNT/beta-catenin signaling pathway in human cancers. Epigenetics 4: 307-312, 2009.

52. Noorolyai S, Shajari N, Baghbani E, Sadreddini S and Baradaran B: The relation between PI3K/AKT signalling pathway and cancer. Gene 698: 120-128, 2019.

53. Petrulea MS, Plantinga TS, Smit JW, Georgescu CE and Netea-Maier RT: PI3K/Akt/mTOR: A promising therapeutic target for non-medullary thyroid carcinoma. Cancer Treat Rev 41: 707-713, 2015.

54. Chen J, Lin C, Yong W, Ye Y and Huang Z: Calycosin and genistein induce apoptosis by inactivation of HOTAIR/p-Akt signaling pathway in human breast cancer MCF-7 cells. Cell Physiol Biochem 35: 722-728, 2015.

55. Hales EC, Taub JW and Matherly LH: New insights into Notch1 regulation of the PI3K-AKT-mTOR1 signaling axis: Targeted therapy of $\gamma$-secretase inhibitor resistant T-cell acute lymphoblastic leukemia. Cell Signal 26: 149-161, 2014.

56. Salmena L, Carracedo A and Pandolfi PP: Tenets of PTEN tumor suppression. Cell 133: 403-414, 2008.

57. Sun H, Lesche R, Li DM, Liliental J, Zhang H, Gao J, Gavrilova N, Mueller B, Liu X and Wu H: PTEN modulates cell cycle progression and cell survival by regulating phosphatidylinositol 3,4,5,-trisphosphate and Akt/protein kinase B signaling pathway. Proc Natl Acad Sci USA 96: 6199-6204, 1999.

58. Yu Y, Lv F, Liang D, Yang Q, Zhang B, Lin H, Wang X, Qian G, $\mathrm{Xu} \mathrm{J}$ and You W: HOTAIR may regulate proliferation, apoptosis, migration and invasion of MCF-7 cells through regulating the P53/Akt/JNK signaling pathway. Biomed Pharmacother 90: 555-561, 2017.

59. Li E, Zhao Z, Ma B and Zhang J: Long noncoding RNA HOTAIR promotes the proliferation and metastasis of osteosarcoma cells through the AKT/mTOR signaling pathway. Exp Ther Med 14: 5321-5328, 2017.

60. Li Z, Qian J, Li J and Zhu C: Knockdown of lncRNA-HOTAIR downregulates the drug-resistance of breast cancer cells to doxorubicin via the PI3K/AKT/mTOR signaling pathway. Exp Ther Med 18: 435-442, 2019.

61. Pan S, Liu Y, Liu Q, Xiao Y, Liu B, Ren X, Qi X, Zhou H, Zeng C and Jia L: HOTAIR/miR-326/FUT6 axis facilitates colorectal cancer progression through regulating fucosylation of CD44 via PI3K/AKT/mTOR pathway. Biochim Biophys Acta Mol Cell Res 1866: 750-760, 2019.

62. Li Z and Luo J: Epigenetic regulation of HOTAIR in advanced chronic myeloid leukemia. Cancer Manag Res 10: 5349-5362, 2018.

63. Luan W, Li R, Liu L, Ni X, Shi Y, Xia Y, Wang J, Lu F and $\mathrm{Xu}$ B: Long non-coding RNA HOTAIR acts as a competing endogenous RNA to promote malignant melanoma progression by sponging miR-152-3p. Oncotarget 8: 85401-85414, 2017.

64. Li T, Qin Y, Zhen Z, Shen H, Cong T, Schiferle E and Xiao S Long non-coding RNA HOTAIR/microRNA-206 sponge regulates STC2 and further influences cell biological functions in head and neck squamous cell carcinoma. Cell Prolif 52: e12651, 2019.

65. Itoh $\mathrm{N}$ and Ornitz DM: Fibroblast growth factors: From molecular evolution to roles in development, metabolism and disease. J Biochem 149: 121-130, 2011.

66. Ke J, Yao YL, Zheng J, Wang P, Liu YH, Ma J, Li Z, Liu XB, Li ZQ, Wang ZH and Xue YX: Knockdown of long non-coding RNA HOTAIR inhibits malignant biological behaviors of human glioma cells via modulation of miR-326. Oncotarget 6 : 21934-21949, 2015 
67. Olsson AK, Dimberg A, Kreuger J and Claesson-Welsh L: VEGF receptor signalling-in control of vascular function. Nat Rev Mol Cell Biol 7: 359-371, 2006.

68. Fu WM, Lu YF, Hu BG, Liang WC, Zhu X, Yang HD, Li G and Zhang JF: Long noncoding RNA Hotair mediated angiogenesis in nasopharyngeal carcinoma by direct and indirect signaling pathways. Oncotarget 7: 4712-4723, 2016.

69. Burger RA: Role of vascular endothelial growth factor inhibitors in the treatment of gynecologic malignancies. J Gynecol Oncol 21: 3-11, 2010.

70. Li Z and Li Z: Glucose regulated protein 78: A critical link between tumor microenvironment and cancer hallmarks. Biochim Biophys Acta 1826: 13-22, 2012.

71. Geng YJ, Xie SL, Li Q, Ma J and Wang GY: Large intervening non-coding RNA HOTAIR is associated with hepatocellular carcinoma progression. J Int Med Res 39: 2119-2128, 2011.

72. Liu XH, Liu ZL, Sun M, Liu J, Wang ZX and De W: The long non-coding RNA HOTAIR indicates a poor prognosis and promotes metastasis in non-small cell lung cancer. BMC Cancer 13: 464, 2013

73. Zhao WH, Yuan HY, Ren XY, Huang K and Guo ZY: Association between expression of HOTAIR and invasiveness of gliomas, and its predictive value. Adv Clin Exp Med 28 : $1179-1183,2019$

74. Kim HJ, Lee DW, Yim GW, Nam EJ, Kim S, Kim SW and Kim YT: Long non-coding RNA HOTAIR is associated with human cervical cancer progression. Int J Oncol 46: 521-530, 2015.

75. Flavahan WA, Gaskell E and Bernstein BE: Epigenetic plasticity and the hallmarks of cancer. Science 357: eaal2380, 2017.

76. Ponting CP, Oliver PL and Reik W: Evolution and functions of long noncoding RNAs. Cell 136: 629-641, 2009.

77. Rinn JL, Kertesz M, Wang JK, Squazzo SL, Xu X, Brugmann SA, Goodnough LH, Helms JA, Farnham PJ, Segal E and Chang HY: Functional demarcation of active and silent chromatin domains in human HOX loci by noncoding RNAs. Cell 129: 1311-1323, 2007.

78. Khalil AM, Guttman M, Huarte M, Garber M, Raj A, Rivea Morales D, Thomas K, Presser A, Bernstein BE, van Oudenaarden A, et al: Many human large intergenic noncoding RNAs associate with chromatin-modifying complexes and affect gene expression. Proc Natl Acad Sci USA 106: 11667-11672, 2009.

79. Ding C, Cheng S, Yang Z, Lv Z, Xiao H, Du C, Peng C, Xie H, Zhou L, Wu J and Zheng S: Long non-coding RNA HOTAIR promotes cell migration and invasion via down-regulation of RNA binding motif protein 38 in hepatocellular carcinoma cells. Int J Mol Sci 15: 4060-4076, 2014

80. Godlewski J, Krichevsky AM, Johnson MD, Chiocca EA and Bronisz A: Belonging to a network-microRNAs, extracellular vesicles, and the glioblastoma microenvironment. Neuro Oncol 17: 652-662, 2015.
81. Fan Q, Yang L, Zhang X, Peng X, Wei S, Su D, Zhai Z, Hua X and $\mathrm{Li} \mathrm{H}$ : The emerging role of exosome-derived non-coding RNAs in cancer biology. Cancer Lett 414: 107-115, 2018.

82. Gezer U, Özgür E, Cetinkaya M, Isin M and Dalay N: Long non-coding RNAs with low expression levels in cells are enriched in secreted exosomes. Cell Biol Int 38: 1076-1079, 2014

83. Ma X, Li Z, Li T, Zhu L, Li Z and Tian NJ: Long non-coding RNA HOTAIR enhances angiogenesis by induction of VEGFA expression in glioma cells and transmission to endothelial cells via glioma cell derived-extracellular vesicles. Am J Transl Res 9: 5012-5021, 2017.

84. Valastyan S and Weinberg RA: Tumor metastasis: Molecular insights and evolving paradigms. Cell 147: 275-292, 2011.

85. Gupta GP and Massagué J: Cancer metastasis: Building a framework. Cell 127: 679-695, 2006.

86. Zhang C, Ji Q, Yang Y, Li Q and Wang Z: Exosome: Function and Role in cancer metastasis and drug resistance. Technol Cancer Res Treat 17: 1533033818763450,2018.

87. Yang $\mathrm{H}, \mathrm{Fu} \mathrm{H}, \mathrm{Xu} \mathrm{W}$ and Zhang $\mathrm{X}$ : Exosomal non-coding RNAs: A promising cancer biomarker. Clin Chem Lab Med 54: 1871-1879, 2016

88. Tang S, Zheng K, Tang Y, Li Z, Zou T and Liu D: Overexpression of serum exosomal HOTAIR is correlated with poor survival and poor response to chemotherapy in breast cancer patients. J Biosci 44: 37, 2019.

89. Wang J, Zhou Y, Lu J, Sun Y, Xiao H, Liu M and Tian L: Combined detection of serum exosomal miR-21 and HOTAIR as diagnostic and prognostic biomarkers for laryngeal squamous cell carcinoma. Med Oncol 31: 148, 2014.

90. Zhang C, Xu L, Deng G, Ding Y, Bi K, Jin H, Shu J, Yang J, Deng $\mathrm{H}$, Wang $\mathrm{Z}$ and Wang Y: Exosomal HOTAIR promotes proliferation, migration and invasion of lung cancer by sponging miR-203. Sci China Life Sci 63: 1265-1268, 2020.

91. Poulet C, Njock MS, Moermans C, Louis E, Louis R, Malaise M and Guiot J: Exosomal long non-coding RNAs in lung diseases. Int J Mol Sci 21: 3580, 2020.

92. Yao Z, Jia C, Tai Y, Liang H, Zhong Z, Xiong Z, Deng M and Zhang Q: Serum exosomal long noncoding RNAs lnc-FAM72D-3 and lnc-EPC1-4 as diagnostic biomarkers for hepatocellular carcinoma. Aging (Albany NY) 12: 11843-11863, 2020.

93. Zhang J, Qiu WQ, Zhu H, Liu H, Sun JH, Chen Y, Shen H, Qian CL and Shen ZY: HOTAIR contributes to the carcinogenesis of gastric cancer via modulating cellular and exosomal miRNAs level. Cell Death Dis 11: 780, 2020.

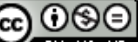

This work is licensed under a Creative Commons Attribution-NonCommercial-NoDerivatives 4.0 International (CC BY-NC-ND 4.0) License. 